Original Research Paper

\title{
Priorities of Value Policy in Race and Ethnic Relations in the USA
}

\author{
Yury Grigoryevich Volkov, Alexander Konstantinovich Degtyarev, \\ Galina Sergeevna Denisova, Valeriya Petrovna Voytenko and Igor Pavlovich Chernobrovkin
}

Institute of Sociology and Regional Studies, Southern Federal University, Russian Federation, Rostov-on-Don, Russia

\author{
Article history \\ Received: 16-07-2016 \\ Revised: 05-12-2016 \\ Accepted: 22-12-2016 \\ Corresponding Author: \\ Yury Grigoryevich Volkov \\ Institute of Sociology and \\ Regional Studies, Southern \\ Federal University, Russian \\ Federation, Rostov-on-Don, \\ Russian \\ Email: infoippk@sfedu.ru
}

\begin{abstract}
Conceptual interpretation of research practices undertaken in this study enabled the authors to identify the specific role of value policy as an efficiency factor of state management in improving race and ethnic relations in the United States. In this regard, the article aims to determine the priorities of value policy, considering the major trends of race relations development in the United States. The methodological basis for the research was formed by a sociological survey representing the formation of the system of core values in contemporary multicultural American society. Using the method of cluster analysis, the authors formed the matrix of social values differentiation according to their impact on race relations. The authors identified two types of values: Incentive values that facilitate improvement of race and ethnic relations and disincentive values which aggravate interracial conflicts. The authors defined and provided rationale for "high", "medium" and "low" influence levels of incentive values on race relations in contemporary American society. The article explains the necessity of subordinated development of disincentive values in contrast to incentive values in value policy related to race relations. Influence levels of incentive values were used to determine the priorities in modern value policy being a factor of social and economic security of the multicultural American society. The findings were processed into conceptual provisions, so that this concept can be used in managing race ethnic relations at the federal level.
\end{abstract}

Keywords: Social Values, Value Policy, Race Relations in the USA, Interracial Conflicts, Ethnic Relations in the USA, Multicultural Nation, Multiculturalism

\section{Introduction}

In the USA, value policy is traditionally seen as a method for managing race and ethnic relations that implies liberal prioritizing of public values to administrative policy of the state. Acknowledging the fact that the USA is a multiracial and multiethnic community causes the need to develop a model of national integration, as well as the system of management what would reflect public values.

American ideology, which is linked to the national (political) identity, explains the cognitive, social and practical interest to the value (axiological) assessment of public policy, which-though clearly manifesting itself in the mid 1990ies (Lubskiy, 2015:8)-persistently set the vector of value policy. American researchers define value policy primarily as implementation of efforts to legitimize public values for the purposes of the US society consolidation. In this regard, the values of individualism, freedom, success, entrepreneurship, individual rights still remain top priorities (Boundless, 2015).

At the same time, researchers register significant changes in the policies concerning ethnic relations and social values, driven by numerous social and political factors that are associated with the approach and evaluation of ethnic and racial differences in the implementation of traditional education programs, unemployment reduction, healthcare (Woolf and Aron, 2013).

In other words, as a component of the system of state regulation, value policy enters the sphere of race and ethnic relations as one of the issues related to maintaining a decent lifestyle and raises an emotional response of American society. Due to the fact that American society still believes in consolidation on the 
basis of generally accepted public values and this idea takes on a new social and political dimension, value policy is seen as a mandatory prerequisite of a growing impact on regulation of race and ethnic relations. Thus, this study aims to identify social values and fundamental priorities of modern value policies implementation as a factor of improving race and ethnic relations in the United States today.

\section{Literature Review}

A critical approach to the paradigm of new public management is linked to the development of the concept of "public values management". The following scientific idea forms the fundamental basis of the concept: Values policy is determined by consistent implementation of the strategy of public policy development and the system of basic social values (Gunkel et al., 2016). Social values are formed in the course of public debate with direct participation of the state (Oskolova, 2014).

As a special kind of management activity, value policy is based on social values. The analysis of terminology shows that scientific sociological discourse encompasses various approaches to understanding the essence of social values. For example, some scientists define values as "deeply rooted ideas on what is good and what is bad" (Bloemraad and Wright, 2014). That is, public values are seen as something bigger than the public welfare, public interest or simply the common good (Cutler, 2015).

Besides, some scholars have a different opinion on the content of social values, by which they understand the limit values that define the interaction in public policy, while collective requests of citizens are formed in the course of social communication" (Volkova, 2013).

However, despite using different conceptual approaches to understanding the essence of values, scientists unanimously acknowledge their binary nature. Binarity manifests itself in the fact that value policy as a management activity can be carried out not only based on the current state of unconscious and conscious public values, but can also be intentionally transformed in the context of the dialogue between the state and society (Bedrik et al., 2016). That is social values are not limited to the public discourse, but they are mandatory requirements to the system of state management and maintenance of interaction in the society and thus have a positive meaning (Frolova et al., 2015). Social values are formed with the state participation, provided that it does not impose priorities on the society, but involves cooperation (Volkova, 2013). Sociologists emphasize the fact that the value cannot be considered public only because it is formulated by government organizations. The public value should be recognized by all citizens, not just some people (Berggren and Nilsson, 2015). That is why the efficiency of value policy is determined by its ability to identify and validate appropriate social values, resolve conflicts of values, promoting the formation of collective public values and preventing "values failure" in the society (Frolova et al., 2015).

Another distinctive feature of modern sociological theory is criticism of value policy as a form of value management. It is criticized for being categoric, monological and ideological. "Axiological policy-as critics note-suggests that some matters were settled outside the political process and thus, politics becomes a means for pursuing a priori positions. Being ideology driven, it suggests that the answers have already been found... Axiological policy discredits the political subjectivity of the actors, be it individuals, large groups or the state as a whole" (Cieciuch et al., 2015). Axiological policy is contrasted with the policy of a dialog which emphasizes pluralism of political activities (Bedrik et al., 2015).

Such a critical attitude to value policy gets perfectly clear if one perceives it as a policy which simply takes into account social values (Zaika, 2015). However, within the neoclassical model of state management value policy is seen as a special type of management which not only focuses on public values, but also creates public values as the foundation of efficient state management. This idea of value policy implies political subjectivity of state management actors to be a prerequisite of value policy (Bedrik et al., 2016).

In the context of increasing international ethnic integration scientists began considering the paradigm of value policy as a tool for resolving interracial and interethnic conflicts, the United States being in the focus of research (Bureiko, 2013; Bedrik et al., 2016). Central methodological issues of studying interracial conflicts include: A typology of cultural values in developing multicultural society (Firat and Boyer, 2015; Jonason et al., 2015); issues of identity (Hanson, 2015); identifying the links between culture and development, between values, institutes and politics (Kim, 2013; Patacchini and Zenou, 2016); processes of cultural transmission (Kim, 2013); the state role in transformation of cultural values of race and ethnic relations (Song, 2014; Shomanov and Zhusupbekova, 2015); formation of social values related to intercultural compatibility (Sobieraja et al., 2013; Kostina et al., 2015). However, as the analysis of scientific papers on race relations shows, there has been yet no fundamental research on priorities of value policy implementation under the changing trends in a developing multicultural society as the basis of social and economic security of the state and as a factor of efficient state management. In this regard, understanding value policy as a specific management practice, the aim of this study is to give conceptual interpretation of the core values of the society as the basis of the efficient value policy in resolving racial and ethnic conflicts on the example of the US multicultural society. 


\section{Analytical Review}

The analysis of the forecasts done by the experts of United States Population Projections shows that by 2060 the US population will increase up to 416 million people, or by almost $31 \%$ compared to 2014 . Even though native-born population makes up the majority of the total US population, it is foreign-born population which demonstrates the fastest growth rate over the analyzed period, its growth in 2060 to amount to $85 \%$ (Fig. 1) (USCB, 2014a). The role of immigration as a factor in the US population growth is increasing with each decade. Today, the country ranks first in the world regarding the number of immigrants-20\% of those living outside of their homeland reside in the United States (USCB, 2014b).

The global study of racial structure of the American population was based on the first general federal census of 1790. The US Census Bureau traditionally defines racial and ethnic identity using the principle of selfidentification, i.e., people themselves determine which race and ethnic group they belong to (FFEU, 2014). According to the US Standards for the Classification of Federal Data on Race and Ethnicity of 1997 it can be said that the racial structure of the US population is one of the most varied in the world (Hobbs and Stoops, 2002). The largest part of the population $(78.7 \%$ as of 2015$)$ is the white race which includes people of European, Middle East or North African origin. However, there is an expected reduction in the white race which would amount to $4.7 \%$ by 2050 , with an increase in the black race (African Americans) by $1 \%$ and Asians by $4.9 \%$. There is also a slight projected reduction in the number of native Hawaiians or Other Pacific Islanders, as well as American Indians or Alaska Natives by $0.1 \%$ (Fig. 2) (WB, 2016; USCB, 2014a).
When giving the demographic prospects for the "white America", one should not forget that during the

twentieth century the annual growth rate of white non-Hispanic population was lower than for all other racial and ethnic groups in the United States and amounted to $1.2 \%$, with $1.4 \%$ for African Americans, 2.3\% -American Indians and Alaska Natives and 4.5\% Asians (WB, 2016). Summarizing these trends, it is possible to conclude that racial and ethnic composition of the American nation is characterized by increasing ethnic diversity, along with a gradual multi-directional change in the proportion of all US racial and ethnic groups and a steady reduction in the share of white Americans.

The formation of the American nation in the framework of the "melting pot" cultural policy is an element of the US state ideology. A unified nation, a community-the carrier of the unified multiculture is created by mixing different races and its constituent ethnic groups in this "melting pot". In modern conditions the consolidation of diverse racial and ethnic migration flows into a varied but unified American nation turns out to be rather inefficient. This statement is proven by the increasing number of racial conflicts in the United States, linked to the fact that it is African Americans who have the highest rates of unemployment and crime. African Americans also demonstrate the lowest educational level and the lowest representation in government and law enforcement agencies. Analyzing the current trends, the authors predict the white race will become a minority over a few decades. The white American society begins to fear the increasing proportion of the people of color and whites isolate themselves and resort to various measures of discrimination, which, in turn, provokes interracial ethnic conflicts in American society.

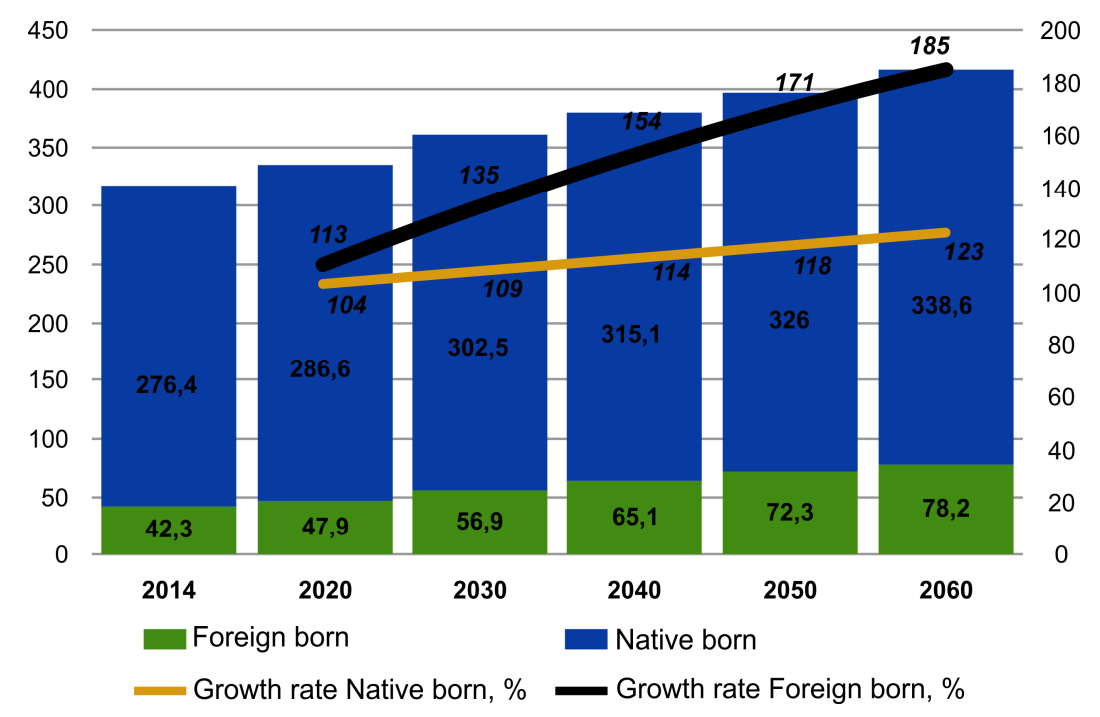

Fig. 1. Dynamics of the US population growth, million people. (Reference rate of growth for $2014, \%$ ) 


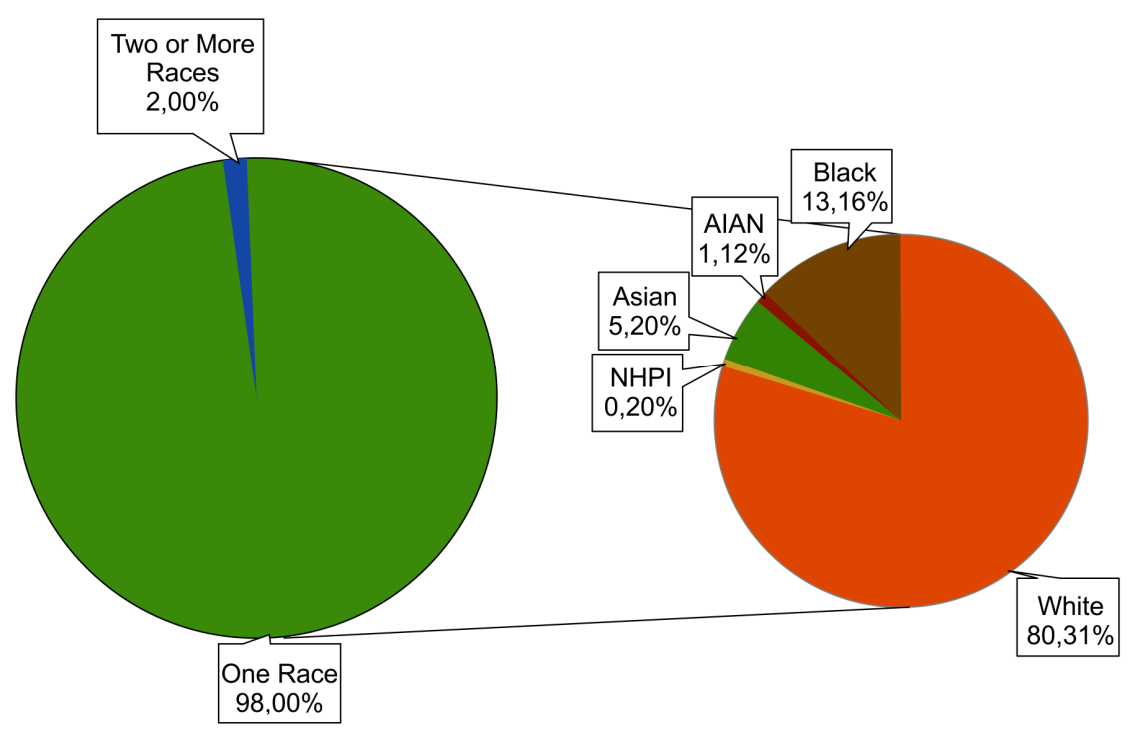

As of 2015

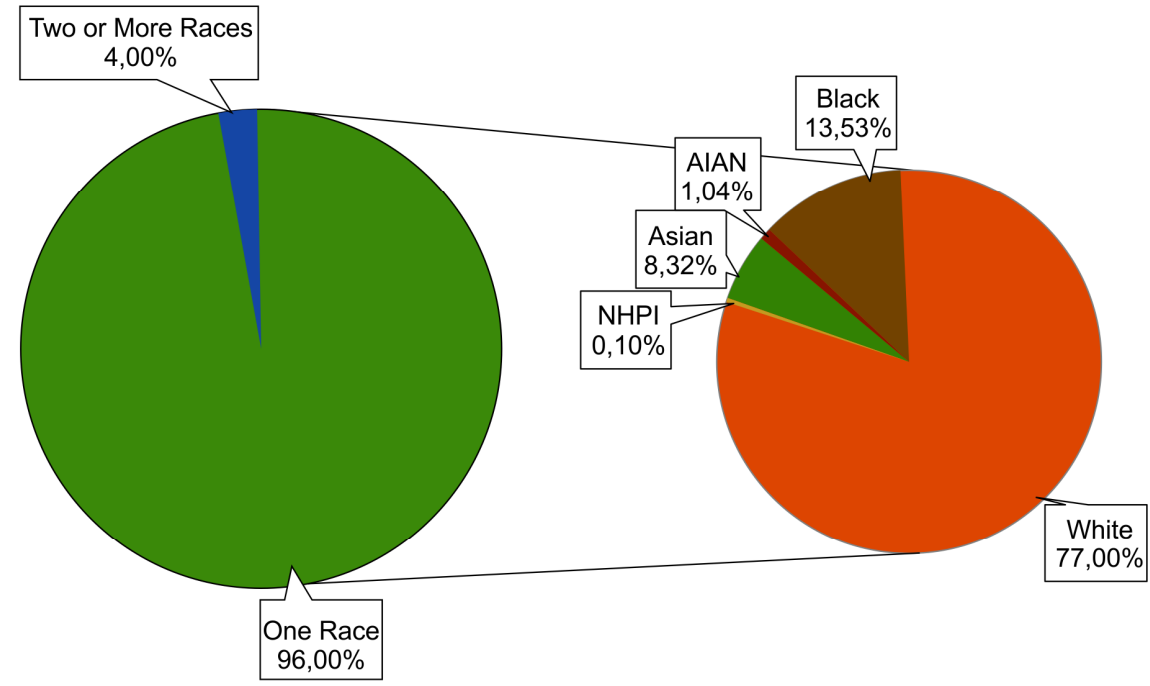

As of 2050

Black = Black or African American;

AIAN = American Indian and Alaska Native;

$\mathrm{NHPI}=$ Native Hawaiian and Other Pacific Islander

Fig. 2. Structure of the US population by race, $\%$

Under current conditions it seems viable to define a set of criteria for those participating in interracial and interethnic relations in order to coordinate efforts aiming at integration into American society. It should be emphasized that value policy separates the competences of government and society in their efforts to prevent ethnic and racial conflicts and to improve the situation in this sphere. Another thing is that this process cannot be expected to be perfectly painless. Regularly occurring interracial conflicts, although caused by the "longstanding" African-American issue, suggest that one should determine the reasons of unabated interracial conflicts, while this phenomenon should be considered not only from the perspective of civil rights and freedoms protection, but also taking into account the fact that interracial relations as relations between "whites", "blacks" and "Asians" are still pressing political matters, with ethnic issues somewhat coming to the fore (Hanson, 2015). 
Thus, it seems undesirable to develop cultural policy exclusively through stimulating and balancing ethnic (cultural) differences in the framework of multiculturalism, as well as to define social and civil rights policies as having "inter-ethnic" content. Clearly, when adopting the convention on the inclusion of the members of different ethnic communities in the public discussion of values, it is viable to reach agreement on how to achieve the civil communication that would satisfy the requests of the citizens, regardless of their race or ethnicity.

In a way value policy is influenced by understanding of the ethnic heterogeneity of American society, when it becomes clear that in the situation of ethnic segregation (voluntary or involuntary) values professed by ethnic groups may be if not "anti-American", then encourage establishing some private rules, creating a parallel network of social communication. In this case the interests of an ethnic community are delegated to the leaders that have influence, larger than the importance of various educational and cultural programs at the municipal level (Song, 2014).

Value policy allows avoiding extreme ethnization since it pursues agreement, rather than ethnic claims. It can be noted that the US value policy becomes a platform for rethinking the existing models of national integration. In addition, value policy, as well as policies in the public discourse, is expected to enable the preservation of the American ethos, belief in universal values. It is possible, firstly, because the public values imply that ethnic groups can influence their representation, but do not declare their own values as special ones. Secondly, the public values equally refer to race and ethnic relations and they are not determined by the formula of the individual rights priority, but aim to support the common good as the general civil idea. Thirdly, public values make it possible to revise the policy, which was linked to the fact that individual rights and economic freedom are the perfect basis for integration into American society and that ethnic differences disappear as an individual achieves success and transforms into an average American. In this regard, this study aims to systematize and prioritize the core values of cultural policy for the purpose of creating a unified multicollinear American nation in the modern context.

\section{Results}

A sociological survey was conducted to determine the system of values that should lie at the heart of the modern value policy for improving race and ethnic relations in the United States. The purpose of the survey was to identify values which, according to Americans, will contribute to the society congregation in the context of racial-ethnic segregation.

The respondents of the survey were the US citizens over 15 years old (whites, African Americans, Native
Americans, Asians and Native Hawaiians). As of 5 July, 2016 the US population over the age of 15 accounts for 260.33 million people (WB, 2016), so for a large universe which is the number of interracial population, the sufficient sample for conducting sociological research was calculated according to the formula:

$$
S S=\frac{Z(\alpha)^{2} \cdot p \cdot(1-p)}{\varepsilon^{2}}
$$

where, SS is a sample size

$\mathrm{Z}(\alpha)$-standard deviation determined according to the selected confidence level (established by the data in Table 1) (Sidnyaev, 2016):

- $\alpha$-Confidence level

- p - Sample variation

- $\varepsilon$ - Margin of error

Valid confidence level at which the results of the study are representative and statistically significant is considered to be $90 \%(\alpha=90 \%)$, with confidence interval $\pm 5 \%$. For given statistical characteristics the survey results will be representative if the sample size is 273 people.

The sample of respondents in this survey is 300 people. Two stages of the survey were carried out by interviews in an international social network Facebook.

At the first stage, respondents were asked to divide a set of basic national values into incentives, the development of which improves ethnic and race relations in society and disincentives which generate and promote ethnic and race conflicts in modern conditions. The value system is formed by literary generalizations. The results of the survey on the differentiation of cultural values into "incentives" and "disincentives" are presented in Table 2.

At the second stage of the sociological survey we determined how strong the influence of incentive values was on escalation of ethnic and racial conflicts in the American society. Thus, for each type of cultural value the respondents were asked to choose one of the options describing the degree of its influence on emergence of ethnic and racial conflicts in the society according to three criteria: "High", "Medium" and "Low". The impact was determined on the basis of directly proportional interference. Low level of influence of a certain cultural value demonstrates that this type of value is developed at a sufficient level in the American society and contributes to the improvement of interethnic relations. The high level of incentive value impact shows that this type of values is poorly developed in the modern society, which contributes to the emergence and development of interracial conflicts.

Disincentive values were examined in the next part of the research since development of these types of cultural values contributes to development and exacerbation of racial conflicts in the United States. 


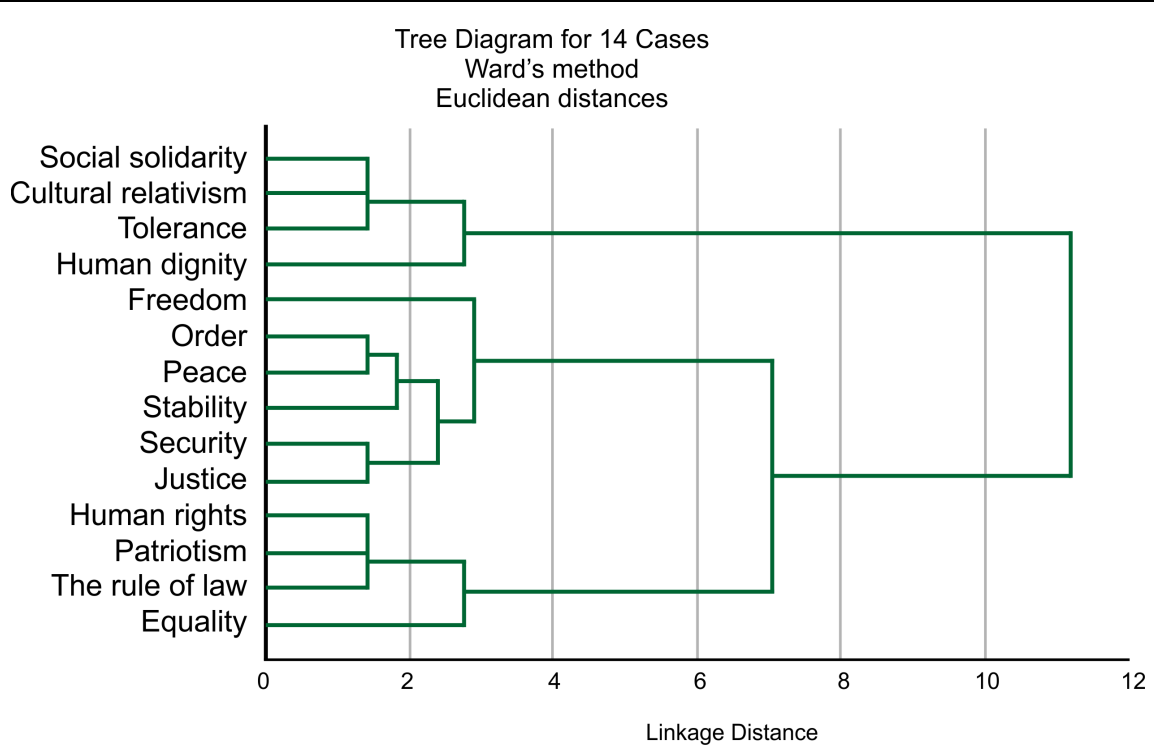

Fig. 3. Clustering of incentive values according to the level of influence on the development of interracial conflicts in the US society

Table 1. Statistical value of standard deviation of the representativeness of respondents sample from the general sample

\begin{tabular}{lllllllll}
\hline$\alpha, \%$ & 60 & 70 & 80 & 90 & 95 & 97 & 99 & 99.7 \\
\hline$Z$ & 0.84 & 1.03 & 1.29 & 1.65 & 1.96 & 2.18 & 2.58 & 3.00 \\
\hline
\end{tabular}

Table 2. Differentiation of cultural values after their influence on race relations in American society according to the results of the sociological survey

\begin{tabular}{ll}
\hline Cultural values & Incentives/Disincentives \\
\hline Social solidarity & Incentives \\
Freedom & Incentives \\
Cultural relativism & Incentives \\
Democracy & Disincentives \\
Human rights & Incentives \\
Human dignity & Incentives \\
Order & Incentives \\
Security & Incentives \\
Justice & Incentives \\
Patriotism & Incentives \\
Equality & Incentives \\
Individual initiative & Disincentives \\
Tolerance & Incentives \\
Conservatism & Disincentives \\
The rule of law & Incentives \\
Peace & Incentives \\
Stability & Incentives \\
\hline
\end{tabular}

Cultural values were grouped through cluster analysis in application software Statistica 10. For purposes of clustering, we considered the respondents' answers as follows: We assigned " 1 " point to the cultural value if it was noted at one of the influence levels. All other levels of the value received " 0 " points. The results of the clustering of cultural incentive values on three levels of influence ("high", "medium" and "low") on the development of inter-racial conflicts in the modern US society are shown in Fig. 3.
Table 3. Differentiation of groups of incentive values according to the level of influence on the development of interracial conflicts in the US society

\begin{tabular}{ll}
\hline $\begin{array}{l}\text { The degree of influence on the existing } \\
\text { ethnic and racial conflicts in society }\end{array}$ & Values \\
\hline Highest degree of influence & Social solidarity \\
& Cultural relativism \\
& Tolerance \\
& Human dignity \\
Medium degree of Influence & Freedom \\
& Order \\
& Peace \\
& Stability \\
& Security \\
& Justice \\
Low degree of influence & Human rights \\
& Patriotism \\
& The rule of law \\
& Equality \\
\hline
\end{tabular}

The findings of the cluster analysis allowed us to identify three groups of cultural values that are capable of improving race and ethnic relations in the USA under modern conditions (Table 3 ).

The highest degree of influence on overcoming racial conflicts in the United States is shown by such values as social solidarity, cultural relativism, tolerance and human dignity. This group contributes to improving interethnic relations and in the modern conditions of resolving the issue of American multiculturalism is characterized by a low level of development.

The medium level of influence on overcoming racial conflicts belongs to such incentive values as freedom, 
order, peace, stability, security and justice. This is the second group of cultural values that should achieve an appropriate development level in contemporary American society after which they would hinder the development of interracial conflicts.

The third group of values comprises human rights, patriotism, the rule of law and equality. This group is the most developed one in modern multi-culture of the American nation and is an important part of the "melting pot" policy. However, the results of the sociological survey indicate a low level of influence for this group of incentive values. Therefore, modern value policy should be aimed at supporting this group of values as a factor in eliminating racial conflicts.

\section{Discussion}

Having analyzed the findings of the study, the authors could rank the values according to their potential for the modern value policy of race relations in American society.

Values that reflect individual personality traits have the greatest influence on improvement of race and ethnic relations. Modern American society should integrate and develop such moral aesthetic ideals as personal and national freedom of the individual, trust to people, state institutions and civil society, justice, mercy, honor, dignity, understanding and respect for other cultures, inner freedom every person has from birth, freedom of choice and display of one's inner world, one's inner self, as well as tolerance of a different worldview, lifestyle, behavior and customs. In the conditions of the growing ethnic heterogeneity of American society this group of values will help narrow the gap between human rights activities focusing on racial groups and practices of multiculturalism aimed at ethnic communities through exchanging values. Currently, American society is formulating a request for a policy of social responsibility and equal representation which involves transition from racial and ethnic (ethno-cultural) division to awareness of differences in interpretation of the public values structure that prevailed in American society and determined their perception as personal ones. The development of personal values will be more influential in race and ethnic relations than mutual coordination of racial and ethnic claims which turned out to be far less effective.

The development of values that ensure the stability of a person's environment (public value) has the medium impact on the elimination of racial conflicts. This group of values implies that American society would integrate such moral ideals as people's ability to choose their lifestyle and occupation themselves, respect and maintenance of the existing social relations between people, the rules of conduct and community life regulated by laws in action, customs, traditions and moral standards. Besides, one is certain that the state, the individual, society and community are protected from internal and external threats, hazards or war, that the situation is stable. This situation is described by the concept of moral consciousness and is regarded as a natural one, reflecting a certain idea of a human's essence and his rights in the state. Another element is the interest in maintaining the stability of American society, as a society with a well-oiled procedure and mechanism of social changes, preserving its stability and eliminating the political struggle which shakes the foundations of a society.

In fact, current Americanization policy still pursues commitment to American ideals and values, but it becomes clear that in the present context the standardization of values of all ethnic groups is hindered by growing ethnic consciousness and voluntary ethnic segregation. The authorities should identify public values and interpret relationships between them. Sustainable development of this group of values will allow combining security and freedom, human rights and civil responsibility. This will also increase the public's interest in value policy that is trying to find the right balance between values of individualism and collectivism, collective representation.

The smallest impact on improvement of race relations in modern conditions is shown by a group of values that includes love of the country, its people, equality of all society members in their status and rights, awareness of the real impact of laws and regulations of the state bodies on the life and future of the society, its structure and individuals. It should be noted that these values reflect the moral ideals of civic consciousness and at present moment they are quite fully integrated in the American society, having developed over a long period of time. However, in light of recent trends in the US racial and ethnic relations, there is a parallel active development of individual and social values. This provision is also true for the category of disincentive values. Active development of such moral ideals as a free expression of people' will, inner motivation to new activities and isolation of various practical and social concepts, rituals, habits and skills, handed down from generation to generation and being a regulator of the social relations, promotes the development of interracial conflicts in the modern multicultural American nation. This group of values has been intrinsic to American society for a long time, but its promotion should comply with the development and integration of personal and public values.

It is worth emphasizing that considering regulation of race and ethnic relations, one should determine how American values can be unified, regardless of ethnicity or race. The method of standardization, though not without occasional failures, has been tested in the field of race relations. However, due to the policy of cultural diversity there is tension in inter-ethnic relations since, one way or another, they generate not only the situation 
of cultural pluralism, but also have the potential for conflict between individual and universal values.

US researchers point out that it would be misleading to expect what government agencies will facilitate the formation of public values through efficient state management (Melkov, 2015). This conclusion stems from the fact that democratic politics primarily focuses not on elimination of the influence of power, but on building a form of power that would be compatible with democratic values. Here we mean that the scope of individual and public values determines government procedures and the effectiveness of state management does not prove the fact that the state or the government can claim to set such values.

US researchers point out that it would be misleading to expect what government agencies will facilitate the formation of public values through efficient state management (Melkov, 2015). This conclusion stems from the fact that democratic politics primarily focuses not on elimination of the influence of power, but on building a form of power that would be compatible with democratic values. Here we mean that the scope of individual and public values determines government procedures and the effectiveness of state management does not prove the fact that the state or the government can claim to set such values.

\section{Conclusion}

Thus, the findings of the empirical research let us conclude the following. The general trend of white race decline in the United States increases the conservatism of race and ethnic relations. This, in turn, escalates interracial conflicts, proving the ineffectiveness of the state social policy of the "melting pot" that implies Americans' forming and developing values representing only the status of the citizen of the country. As part of empirical research, the authors classified cultural values according to the levels of influence on the development of inter-racial and inter-ethnic conflicts in the United States, which consisted of two categories-incentive values and disincentive values. Such an approach, in contrast to the existing methodology of value policy regarding race relations, allowed identifying social solidarity, cultural relativism, tolerance and human dignity as the main types of individual values that should form the basis of modern value policy in the United States. On the other hand, values such as cultural universalism, democracy, individual initiative and conservatism promote inter-racial conflicts, the development of which should comply with incentive values. The issues of formation, development and integration of core incentive values should become top priorities, whereas consistent playing down disincentive values in American society will contribute to the improvement of race and ethnic relations in the country. This would enable the diversity of instrumental values, while maintaining the priority of the integrating fundamental values. It will also neutralize effects of racialization and ethnicization, reducing their impact in the social sphere, which in turn prevents one from perceiving racial and ethnic stereotypes as significant compared to the basic American values.

\section{Acknowledgment}

The authors gratefully appreciate the support of the Russian Science Foundation grant.

\section{Funding Information}

The article is made within the framework of the Russian Science Foundation grant No. 15-18-00122 "Institutional practices and value policy in the sphere of harmonization of interethnic relations in the economically developed countries with complex ethnic and cultural structure: Comparative analysis and modeling of implementation in the Russian context".

\section{Author's Contributions}

The authors have equally contributed to the conducted research and writing of the article.

\section{Ethics}

This article is original and contains unpublished material. The authors confirm that there are no ethical issues involved.

\section{References}

Bedrik, A.V., I.P. Chernobrovkin, A.K. Degtyarev, A.V. Serikov and N.A. Vyalykh, 2015. The management of inter-ethnic relations in Germany and the United States: The experience of the theoretical comprehension. Mediterranean J. Social Sci., 6: 87-92. DOI: $10.5901 /$ mjss.2015.v6n4s4p87

Bedrik, A.V., I.P. Chernobrovkin, A.V. Lubskiy, Y.G. Volkov and N.A. Vyalykh, 2016. Value policy: Conceptual interpretation of research practices. Ind. J. Sci. Technol., 9: 1-6. DOI: $10.17485 / \mathrm{ijst} / 2016 / \mathrm{v} 9 \mathrm{i} 5 / 87598$

Berggren, N. and T. Nilsson, 2015. Globalization and the transmission of social values: The case of tolerance. J. Comparat. Econom., 43: 371-389.

DOI: $10.1016 /$ j.jce.2015.02.005

Bloemraad, I. and M. Wright, 2014. "Utter Failure" or unity out of diversity? Debating and evaluating policies of multiculturalism. Int. Migrat. Rev., 48: 292-334. DOI: 10.1111/imre.12135 
Boundless, 2015. From Political Values to Ideology. Boundless Political Science.

Bureiko, N.N., 2013. Impact of Immigration on Formation of the American National Identity. Studia Humanitatis.

Cieciuch, J., S.H. Schwartz and E. Davidov, 2015. Values, Social Psychology of. In: International Encyclopedia of the Social and Behavioral Sciences, Wright, J.D. (Ed.), Elsevier Science, Amsterdam, ISBN-10: 0080970877, pp: 41-46.

Cutler, T., 2015. New managerialism and new public sector. Manage. Int. Encycl. Social Behav. Sci., 2: $770-775$.

FFEU, 2014. The foundation for ethnic understanding.

Firat, R.B. and P. Boyer, 2015. Coalitional affiliation as a missing link between ethnic polarization and wellbeing: An empirical test from the European social survey. Social Sci. Res., 53: 148-161. DOI: 10.1016/j.ssresearch.2015.05.006

Frolova, A.S., A.V. Lubsky, O.Y. Posukhova, A.V. Serikov and Y.G. Volkov, 2015. Ideological grounds for settlement of inter-ethnic relations in modern Russia: Competition of ideas and ideology of humanism. Mediterranean J. Social Sci., 6: 58-63. DOI: $10.5901 / \mathrm{mjss} .2015 . v 6 \mathrm{n} 4 \mathrm{~s} 4 \mathrm{p} 58$

Gunkel, M., C. Schlaegel and V. Taras, 2016. Cultural values, emotional intelligence and conflict handling styles: A global study. J. World Bus., 51: 568-585. DOI: $10.1016 /$ j.jwb.2016.02.001

Hanson, V.D., 2015. Ethnic identity pointless in America. Washington Times.

Hobbs, F. and N. Stoops, 2002. Demographic Trends in the 20th Century: Census 2000 Special Reports. 1st Edn., U.S. Department of Commerce, pp: 163.

Jonason, P.K., G.L. Strosser, C.H. Kroll, J.J. Duineveld and S.A. Baruff, 2015. Valuing myself over others: The dark triad traits and moral and social values. Personality Individual Diff., 81: 102-106. DOI: $10.1016 /$ j.paid.2014.10.045

Kim, H.H., 2013. Transnational ethnic networks and the creation of immigrant social capital: A multilevel analysis. Social Sci. J., 50: 349-358.

DOI: $10.1016 /$ j.soscij.2013.04.012
Kostina, E., L. Kretova, R. Teleshova, A. Tsepkova and T. Vezirov, 2015. Universal human values: CrossCultural comparative analysis. Proc Social Behav. Sci., 214: 1019-1028.

DOI: $10.1016 /$ j.sbspro.2015.11.696

Lubskiy, A.V., 2015. Public intellectuals and political cynicism. Polit. Conceptol., 2: 204-216.

Melkov, S.A., 2015. Yankees everywhere: Where is Home? Authority, 4: 25-28.

Oskolova, T.L., 2014. Evolution of national identity in the educational paradigm of Australia and the United States: The path from assimilation to multiculturalism. Bull. Tyumen State University. Socio-Econom. Legal Stud., 9: 92-100.

Patacchini, E. and Y. Zenou, 2016. Racial identity and education in social networks. Social Netw., 44: 85-94. DOI: 10.1016/j.socnet.2015.06.001

Shomanov, N.T. and M.K. Zhusupbekova, 2015. Theoretical and methodological aspects of research on international relations issues. Adv. Curr. Natural Sci., 1: 528-531.

Sidnyaev, N., 2016. Theory of Experiment Design and Statistical Data Analysis. Urayt, Moscow.

Sobieraja, S., J.M. Berry and A. Connors, 2013. Outrageous political opinion and political anxiety in the US. Poetics, 41: 407-432.

DOI: $10.1016 /$ j.poetic.2013.06.001

Song, M., 2014. Raising the bar in analysis: Wimmer's ethnic boundary making. Ethnic Racial Stud., 37: 829-833. DOI: 10.1080/01419870.2013.871312

USCB, 2014. National Projections, U.S. Census Bureau.

USCB, 2014. Statistical Abstract of the United States: 2011. Section 1. Population, U.S. Census Bureau, pp: 62 .

Volkova, A.V., 2013. Public Values and the System of State Management in Russia. St. Petersburg State University Press, St. Petersburg.

WB, 2016. The World Bank Group.

Woolf, S. and L. Aron, 2013. U.S. Health in International Perspective: Shorter Lives, Poorer Health. National Academies Press, ISBN-10: 0309264146, pp: 420.

Zaika, K.V., 2015. Models of national integration in the context of increasing immigration flows. World Economy Int. Relat., 6: 59-70. 